\title{
Corporate insolvency law reform
}

\section{Trish Keeper, Victoria University of Wellington, on the new voidable dispositions regime, changes to related party voting rules and volun- tary liquidations}

\section{INTRODUCTION AND BACKGROUND}

?

he Insolvency Practitioners Regulation (Amendments) Act 2019 (the Amendment Act) was enacted in June 2019, although it is not in force yet. Although there is no purpose section in this Act, it was passed at the same time as the Insolvency Practitioners Regulation Act 2019 (IPR Act) as both Acts were divided from the Insolvency Practitioners Amendment Bill 2010 (the Bill) in 2018. The purpose of the IPR Act is identified in s 3 as an Act to regulate insolvency practitioners and to establish an independent oversight system. Also, the Amendment Act will largely come into force in mid-2020 at the same time as the IPR Act and therefore one might think that the sole focus of the Amendment Act is to amend associated provisions in related legislation as part of the new licensing regime for insolvency practitioners. To a large extent, this assumption is correct. For example, the Amendment Act does modify the current qualification provisions in the Companies Act 1993 and the Receivership Act 1993 as to liquidators and receivers respectively.

However, the Amendment Act also contains several unrelated changes to New Zealand's corporate insolvency laws. These reforms include the establishment of a new insolvent disposition regime, the reversal of the presumption in respect of related party voting at creditors meetings and amendments to the voluntary liquidation procedure. Each of these amendments is discussed separately below after the following summary of the background to the reforms.

The immediate impetus for the co-regulatory design for the new insolvency practitioner regulatory regime was the recommendations of a 2016 Insolvency Working Group (IWG). The IWG was a panel of insolvency law experts appointed by the Ministry of Business, Innovation and Employment (MBIE) principally to advise on the better regulation of insolvency practitioners in New Zealand. The first report of IWG (Review of Corporate Insolvency Law: Report No. 1 of the Insolvency Working Group, on insolvency practitioner regulation and voluntary liquidations (MBIE, 2016)) recommended a co-regulatory system be adopted and this recommendation was incorporated into the Bill by Supplementary Order Paper in 2018 (SOP 45). The IWG's Terms of Reference also included making recommendations on other potential improvements to New Zealand's corporate insolvency laws (MBIE, Terms of Reference, Insolvency Review Working Group (2015) at 2). Most of the IWG's additional recommendations are set out in its second Report (Review of Corporate Insolvency Law: Report No 2 of the Insolvency Working Group, on voidable transactions, Ponzi schemes and other corporate insolvency matters, May 2017).

\section{VOIDABLE DISPOSITIONS}

The Amendment Act, when it is in force, will introduce into the Companies Act 1993 a new voidable disposition regime in ss 296A-296D. Under s 296A, any disposition of company property within the specified period is voidable. Section 296A(2) provides that the specified period begins on the date on which the application is made to the High Court to appoint a liquidator under s 241(2)(c) and ends at the time the liquidator is appointed (or the court otherwise disposes of the application). Any disposition during this period is voidable against a liquidator, except if it was made in the ordinary course of business, or it was made by an administrator, deed administrator or receiver on behalf of the company or under an order of the court.

The IWG recommended the addition of this new regime to restrict the transfer of a company's assets in the period between the date of an application to appoint a liquidator being filed and a liquidator being subsequently appointed by the court. In some parts of the country, this can be a period of up to three months. The IWG, in its second Report at [193], observed that "the liquidation application is often the signal for a rapid transfer of assets, often at undervalue or at no value, by shareholders and directors prior to the appointment of a liquidator". Furthermore, it was noted that this harm is particularly acute when the parties involved are adopting phoenix strategies. Finally, the IWG observed that such transfers are occurring, notwithstanding the current provisions empowering a liquidator to recover differences in value contained in ss 297 and s 298 of the Companies Act.

A new section, s 296A(3), provides that the terms 'disposition' and 'property' have the same meaning as set out in s 345 of the Property Law Act 2007 (PLA). Section 345(2)(f) defines 'disposition' in broad terms and includes any "transaction entered into by a person with intent by entering into the transaction to diminish, directly or indirectly, the value of the person's own estate and to increase the value of the estate of another person". 'Property' in s 345 of the PLA is defined for the purposes of that subpart of the PLA as including the proceeds of any property. The term 'property' is more generally defined in s 4 of PLA as everything capable of being owned, whether it is real or personal property, and whether it is tangible or intangible property; and includes any estate or interest in property. Interestingly, the Bill as amended by SOP 45 proposed that property subject to this clawback be limited to non-current assets, but following submissions on this issue, the provisions apply to all assets transferred within the specified period.

The advantage of the new clawback provision from a liquidator's viewpoint is that the default position is that any disposition in the specified period is voidable without the 
[2020] NZLJ 10

evidential issues faced by a liquidator seeking to clawback assets of the company transferred at under value under the existing ss 297-298. New sections, ss 296B and C, set out the notice and defence rules for the new regime, which replicate those that apply to voidable transactions in ss 294-296.

However, there are potentially some problems with the new clawback provisions. There is some overlap between the existing insolvent transaction rules in s 292 and the new regime. All insolvent transactions will be insolvent dispositions, but not vice versa given the requirement in s 292(2)(b) for the recipient of an insolvent transaction to receive more towards the satisfaction of their debt than they would otherwise receive in the liquidation. The insolvent transaction rules were amended in 2007 when the 'ordinary course of business' exception was removed, and the running account netting provision was added. The running account netting rules in s 292(4B) only apply to payments to a creditor which are an integral part of a continuing business relationship with that creditor. By definition, any payment to a one-off creditor is thereby excluded. However, the exception for any ordinary course of business transactions in the new s 296A will cover payments to one-off trade creditors as well as long term suppliers. One note of caution is that the reason for the removal of the 'ordinary course of business' exception from s 292 was the significant confusion in practice as to what transactions it covered and had given rise to a considerable degree of litigation. There is potential for the same difficulties to arise again.

Another potential difficulty for a board is that the start of the restricted period is stated to be the date that an application for a court-appointed liquidator is filed. A board may inadvertently make a disposition after the date of filing and before notice of that fact is served on the company. Although, any transfer in this period may be protected from clawback due to the operation of $\mathrm{s} 296 \mathrm{~B}$, which protects bona fide third parties, who are without knowledge of the insolvent position of the company, the disposition itself would still be in breach of the Act and potential expose the board to a breach of duty claim.

Finally, and likely to be the most problematic in practice, the risk than any transaction that occurs after the application to liquidate has been filed is voidable as against the liquidator, is likely to act as a disincentive to any restructure or arrangement to secure new finance for the company on the brink of insolvency. This is a point that was raised by the Restructuring, Insolvency and Turnaround Association of New Zealand (RITANZ) and others in their submissions on SOP 45. Although these concerns were dismissed by MBIE, it is unclear whether the fact that the onus will be on a recipient of a disposition to prove that it should not be set aside will deter bona fide purchasers or financiers who have knowledge of a pending liquidation application.

\section{NEW RESTRICTIONS ON RELATED PARTY VOTING AT CREDITOR MEETINGS}

Less controversial are the amendments to the related party creditor voting rules set out in the Companies Act which apply to creditors meetings for a company in voluntary administration (s 239AM) and a company in liquidation (s 245A). The current rules provide that related party votes are only discounted if a court so orders following an application of an administrator or liquidator. The new provisions reverse this approach. Once in force, a related creditor's vote on a resolution at a creditor's meeting held under pt $15 \mathrm{~A}$ or pt 16 will be automatically disregarded, unless a court orders otherwise.

Guidance is given to a court as to the factors which a court should take into account when making such orders (s 239A(2B) and s $245 \mathrm{~A}(2 \mathrm{~b}))$. In addition, the Amendment Act introduces a number of new provisions to the Companies Act 1993. Sections 239AMA and 245B provide that a related creditor before the meeting occurs may apply for a court order that their vote be taken into account. Only a related party can apply for a court order as the new rules do not provide for an application by the administrator or liquidator. For example, an administrator may wish for a related party to vote, if the company in administration is part of a corporate group and only has related party debt and no external third party debt.

The new rules also set out the procedure that applies if a creditor votes at a meeting who the administrator or liquidator considers to be a related party. In this case, the practitioner must (unless the court directs otherwise) disregard the vote and give notice to the creditor of the reasons for the practitioner's decision. The related creditor may still apply to the court for an order that its vote is taken into account. If, after the meeting, an insolvency practitioner discovers that a creditor who voted on a resolution was an (undisclosed) related creditor, and the resolution would not have been passed or defeated if the votes cast by the related creditor had been disregarded, then the practitioner must notify the other creditors and also has the power to apply to the court for the relevant resolution to be set aside. However, until the court makes such an order, the resolution in question is still valid.

\section{VOLUNTARY INSOLVENT LIQUIDATIONS}

The Terms of Reference for the IWG expressly identified voluntary liquidations, especially when used by boards and others seeking to avoid liability, as an area of corporate law that required reform. This procedure, set out in s 241AA of the Companies Act, provides that after an application is filed at court to appoint a liquidator, the company only has 10 working days after service of that notice to appoint a liquidator. However, while there is a time limit on the appointment of a liquidator, under the current rules, there are very few restrictions on who can be appointed as a liquidator by the company. The IWG in Report No 1 at 33 observed that this gap in the law allows a company to appoint a "debtor-friendly, incompetent or dishonest liquidator" to that role.

A number of submissions to the Select Committee, which considered the 2018 version of the Bill (as amended by SOP $45)$, suggested that s 241AA should be deleted from the Act once the new licensing system for insolvency practitioner is in force. Under the new regime, any company that is unable at the time of appointment to satisfy the solvency test must appoint a licensed, independent liquidator. However, MBIE, in its advice to the Select Committee, recommended the section be retained to encourage debtor companies to make early appointments (that is, within 10 days) and that while the licensing regime will reduce the incidence of debtorfriendly appointments, MBIE was of the view that this will not totally resolve the issue (MBIE Insolvency Practitioners Bill, Supplementary Order Paper No 45: Departmental Report

Continued on page 41 


\section{[2020] NZLJ 37}

IHL until a complete set of laws of armed conflict is formulated. A contemporary version of the clause included in art 1.2 of the Protocol I to the Geneva Conventions reads:

In cases not covered by this Protocol or by other international agreements, civilians and combatants remain under the protection and authority of the principles of international law derived from established custom, from the principles of humanity and from the dictates of public conscience.

The Martens clause warrants a minimal scope of protection under IHL, in the absence of directly applicable treaties. Novel, disruptive technologies create unforeseen conditions for the protection of civilians. This aspect of complete uncertainty permits the invocation of the Martens clause in the case of LAWS. Despite the application of the Geneva Conventions to the use of LAWS, it is worth stressing that the technology cannot comply with the rules that protect civilians. Indeed, both HRW and the IHRC maintain that LAWS would be unable to comply with the "principles of humanity" and "dictates of public conscience" that define the extent of protection of the Martens clause.

In contrast, promoters of LAWS argue that LAWS could better protect human life than human soldiers do and that it is "premature to classify LAWS as inhuman as the large-scale operational implications of employing such technology are just now being studied" (Brian Hall "Autonomous Weapons Systems Safety” (2017) JFQ Washington 86 at 93).

Against optimistic promoters of LAWS, the newness of the technology and the number of interfaces that it comprises allows critics to categorise LAWS as high-risk technologies. In such technologies, the potential for catastrophic effects, when one of the components fails, is extremely high. As in nuclear technologies, a "normal" rate of accidents thwarts the protection of human life and the capability to respect human dignity.
As the discussion takes place, New Zealand will have to make a political decision concerning the nation's stance in connection with the UN's call to ban killing robots. New Zealand's Foreign Minister, Winston Peters, gave an ambivalent statement in the letter sent to the campaign for banning LAWS (Andrea Vance, above).

Our priority is to ensure that current international law is implemented more effectively to ensure there will always be meaningful human control over weapons incorporating autonomy ... New Zealand has lent its support to calls for a high-level political declaration that would set out key disciplines on the development and use of Laws, such as meaningful human control and the operational safeguards needed to ensure them ... The political declaration we seek would not exclude progress on other options over time, but at this stage it is clear that major countries capable of developing Laws would not join a ban. We support a forward work programme that ensures that discussions can continue among a wide grouping of states on key technical, policy and legal issues relating to Laws, including issues involved in a possible ban.

The letter displays the tension that New Zealand experiences as the country's technological capability grows sufficiently to develop its own army of LAWS while considering the inherent danger that other countries with LAWS create. Humanity seems to have learned some of the lessons of human suffering caused by wars, lessons that led to the ban of chemical weapons and the more recent 2008 Convention on Cluster Munitions among many more conventions restricting dangerous technologies for war.

The occasion has come for the country to openly discuss the advantages and dangers that LAWS carry, and to make a decision. Will New Zealand honour its past as a guardian for the protection of civilians, as when it bravely challenged the nuclear arms race? Time will tell.

\section{Continued from page 11}

to the Economic Development, Science and Innovation Committee (19 October 2018) at 36-38).

Accordingly, s 241AA has been retained, albeit in an amended form. Once the Amendment Act is in force, shareholders or directors will only be able to appoint a liquidator, after the company has been served a notice of an application for the court to appoint a liquidator under s 241(2)(c), in two situations. First, if an application for a court appointed liquidator was not made by a creditor of the company, then under new s $241 \mathrm{AA}(2)(\mathrm{a})$, the voluntary appointment must take place within 10 days of the service. Alternatively, under s $241 \mathrm{AA}(2)$ (b) if a creditor has made the application, then that creditor must consent to the liquidator appointed by the shareholders or directors. It is unclear, in the section as drafted, if the 10-day window applies in this situation, although this was MBIE's intention.

However, the amended provision may create some difficulties in practice. If the company fails to appoint a liquidator within the time limit, the board and the shareholders arguably are in limbo awaiting the eventual appointment of a liquidator by the court. Furthermore, the new voidable disposition regime may deter restructuring attempts which may further reduce and restrict any measures to improve the financial position of the company. Secondly, as the IRD is the petitioning creditor for a significant number of all applications for a court appointed liquidator, the company will need to obtain the IRD approval of a proposed liquidator. It is likely that the IRD will only approve those practitioners on its preferred panel. This will extend the 'closed shop' whereby practitioners on the IRD preferred panel are exclusively appointed by the court to encompass 'voluntary' appointments by the company.

\section{CONCLUSION}

The changes to the Companies Act 1993 outlined in this article are all designed to remedy identified deficiencies in the law. It will be interesting to see how these provisions are applied in practice and whether they achieve their intended purposes. 